\title{
Introduction: The Problem of Entertaining Violence
}

The impetus for this special issue of Projections was personal, not just academic. I am deeply, religiously committed to nonviolence. I have three sons and a daughter that I have tried to raise to share this commitment. Yet I really relish the occasional violent entertainment and I have been fairly free in sharing this pleasure with my children. This has led to considerable moral anxiety.

For several years, searching for practical answers to my moral qualms, I immersed myself in the scientific literature on media violence. From this research, I arrived at two main conclusions. First, there is an actual correlation between use of violent entertainments and a tendency toward antisocial behavior, particularly among children. Even though there is no direct causal link between virtual violence and actual violence, there is strong evidence for a systemic connection. That is a genuine cause for concern. My second conclusion is that most of the folks who do scientific research into violent entertainments do not enjoy them much or, if they do, they hide it well. They tend to ignore or frankly dismiss the pleasure and other positive outcomes of violent movies and video games. For this reason, their conclusions have been of little help to me in seeking practical solutions to my own moral quandary.

Humanities scholars who write about violent entertainments have a far more nuanced understanding. They acknowledge both what is disturbing and what is appealing about violent entertainments. Conversely, the explanations they offer of the psychological and behavioral impact of violent entertainments (if they bother to offer such explanations at all) tend to be speculative, impressionistic, and not terribly well informed by the empirical literature. Thus I have not found a lot of solid practical guidance there, either.

My own article in this issue is an attempt to navigate a path through this moral dilemma - to figure out how (or, indeed, if) it is possible to square renunciation of actual violence with appreciation of virtual violence. My conclusion is guardedly optimistic. There is no question that when you pay \$10 to see Expendables 2 or $\$ 60$ to buy Call of Duty: Black Ops I/ you are supporting a culture of violence by helping (i.e., paying) to disseminate ideas of violence. This ought to concern the pacifist, just as it ought to concern the pacifist that pay- 
ing US income taxes supports a bloated military machine. However, the virtual violence of fiction films and video games is not actual violence, nor does it necessarily promote actual violence. The best prophylaxis against actual violence is the practice of empathy, reason, and self-control. In a healthy, nonviolent social environment, violent entertainments can and often do work to promote this practice.

Several other articles in this issue grapple with somewhat the same problem-squaring appreciation of virtual violence with dismay at what it represents. William Brown argues that certain extreme depictions of violence can prompt a particularly ethical form of engagement with movies. Rikke Schubart observes that the emotions elicited by violence in popular vampire and zombie TV series include the socially positive emotions of trust, hope, and desire. Henry Bacon theorizes that some of the appeals of cinematic violence are connected to the sustenance of communities and the control of aggressive impulses. Focusing on the dark side of violent entertainments, Will Gartside argues that the Saw and Hostel movies have the effect of rationalizing and trivializing actual torture. And in an empirical vein, Ron Tamborini and his colleagues report on the findings of an experiment devised to tease out which components of virtual violence matter most to viewers. The issue concludes with reviews of two recent books that, together, illustrate the diversity of approaches in the humanities to the topic of entertaining violence.

It is clear that the problem of violence in our culture is not going to go away any time soon. At the same time, our society is becoming increasingly mindful of and knowledgeable about pathologies of violence, from playground bullying to mental illness. Film and media scholars can contribute to that mindfulness by offering more thoughtful and informed discussions of the role and the impact of media violence. I believe that this special issue of Projections makes a worthwhile contribution to that conversation.

Dirk Eitzen 